\title{
Interleukin-6 and tumor necrosis factor- $\alpha$ are not increased in patients with Type 2 diabetes: evidence that plasma interleukin-6 is related to fat mass and not insulin responsiveness
}

\author{
A. L. Carey ${ }^{1}$ C. R. Bruce ${ }^{2}$ M. Sacchetti ${ }^{3}$ M. J. Anderson A D. B. Olsen $^{3}$ • B. Saltin ${ }^{3}$ J. A. Hawley ${ }^{2}$ \\ M. A. Febbraio ${ }^{1}$ \\ ${ }^{1}$ Skeletal Muscle Research Laboratory, School of Medical Sciences, RMIT University, Bundoora 3083, Victoria, Australia \\ 2 Exercise Metabolism Group, School of Medical Sciences, RMIT University, Bundoora, Victoria, Australia \\ ${ }^{3}$ Copenhagen Muscle Research Centre, University of Copenhagen, Copenhagen, Denmark \\ ${ }^{4}$ Department of Physiology, The University of Melbourne, Parkville, Victoria, Australia
}

\section{Abstract}

Aims/hypothesis. Our aim was to examine the possible direct relationship of interleukin-6 and TNF $\alpha$ with insulin sensitivity in humans.

Methods. We carried out two series of euglycaemichyperinsulinaemic clamp experiments. In the first (CLAMP1), skeletal muscle mRNA expression and plasma concentrations of IL-6 and TNF $\alpha$ were examined in patients with Type 2 diabetes $(n=6)$, subjects matched for age $(n=6)$, and young healthy $(n=11)$ control subjects during a 120-min supra-physiological hyperinsulinaemic $\left(40 \mathrm{mU} \cdot \mathrm{m}^{-2} \cdot \mathrm{min}^{-1}\right)$ euglycaemic clamp. In the second series of experiments (CLAMP2), patients with Type 2 diabetes $(n=6)$ and subjects matched for age $(n=7)$ were studied during a 240 -min high-physiological hyperinsulinaemic $\left(7 \mathrm{mU} \cdot \mathrm{m}^{-2} \cdot \mathrm{min}^{-1}\right)$ euglycaemic clamp, during which arterial and venous (femoral and subclavian) blood samples were measured for IL- 6 and TNF $\alpha$ flux.

Results. In both experiments the glucose infusion rate in the patients was markedly lower than that in the other groups. In CLAMP1, basal skeletal muscle IL-6 and $T N F \alpha$ mRNA were the same in all groups. They were not affected by insulin and they were not related to the glucose infusion rate. In CLAMP2, neither cytokine was released from the arm or leg during insulin stimulation in either group. In both experiments plasma concentrations of these cytokines were similar in the patients and in the control subjects, although in CLAMP1 the young healthy control group had lower $(p<0.05)$ plasma IL-6 concentrations. Using data from all subjects, a strong positive correlation $(r=0.85 ; p<0.00001)$ was observed between basal plasma IL-6 and BMI. Conversely, a negative relationship $(r=-0.345 ; p<0.05)$ was found between basal plasma TNF $\alpha$ and BMI, although this was not significant when corrected for BMI. When corrected for BMI, no relationship was observed between either basal plasma IL-6 or TNF $\alpha$ and GIR.

Conclusions/interpretation. These data show that the increased circulating IL-6 concentrations seen in patients with Type 2 diabetes are strongly related to fat mass and not insulin responsiveness, and suggest that neither IL-6 nor $\mathrm{TNF} \alpha$ are indicative of insulin resistance.

Keywords Cytokines - Glucose disposal · Insulin resistance Skeletal muscle
Received: 9 December 2003 / Accepted: 29 March 2004

Published online: 28 May 2004

(C) Springer-Verlag 2004

M. A. Febbraio (๘)

Skeletal Muscle Research Laboratory,

School of Medical Sciences, RMIT University, PO Box 71,

Bundoora 3083, Victoria, Australia

E-mail: mark.febbraio@ rmit.edu.au

Tel.: +61-3-99257305, Fax: +61-3-99257083

Abbreviations: CLAMP1, First series of experiments . CLAMP2, Second series of experiments - CON1, Healthy, sedentary, age- and BMI-matched control subjects in

\section{Introduction}

The cytokines interleukin (IL)-6 [1, 2, 3] and tumor necrosis factor (TNF) $\alpha[3,4,5]$ have been implicated in causing insulin resistance in patients with obesity

CLAMP1 - CON2, Healthy, sedentary, age- and BMI-matched control subjects in CLAMP2 - D1, Patients with Type 2 diabetes in CLAMP1 - D2, Patients with Type 2 diabetes in CLAMP2 - GIR, Glucose infusion rates · YOUNG, younger control subjects in CLAMP1 
and Type 2 diabetes, although this remains equivocal. Obesity and/or insulin resistance is associated with an IL-6 gene polymorphism [6], higher plasma concentrations of IL-6 [3, 7] and IL-6 release from adipose tissue [8]. However, there is little evidence to suggest that IL-6 negatively affects insulin action in vivo. To the contrary, it has been shown that recombinant human IL-6 infusion into healthy humans does not result in impaired glucose disposal [9], whereas IL-6 knockout mice become overweight and glucose intolerant with advanced age, effects that are partially reversed after replacement of IL-6 [10]. Of note, 10 to $35 \%$ of the body's circulating IL- 6 is derived from adipose tissue [11], although neither the precise biological role [12] nor the source of the remaining secreted IL-6 is known. Therefore, IL-6 is possibly increased in patients with impaired insulin action as a consequence of the increased fat mass rather than being associated with insulin resistance per se. This has never been investigated experimentally, but from a clinical perspective it is important to determine if increased circulating IL-6 is related to insulin sensitivity as measured during a hyperinsulinaemic-euglycaemic clamp, an accurate measure of insulin sensitivity. We hypothesised that circulating IL-6 would correlate with indices of adiposity and be independent of insulin responsiveness. Furthermore, since adipose-tissue-derived plasma IL-6 accounts for onethird of the total circulating levels, and skeletal muscle can produce significant amounts of IL-6 during muscular work $[13,14]$, we aimed to determine if resting limbs would produce significant amounts of this cytokine.

We have shown previously [15] that $I L-6$ mRNA is found in greater quantities in insulin-resistant rodent skeletal muscle after insulin stimulation compared with healthy muscle, whereas IL-6 is expressed and released from skeletal muscle during contractions [13, 16]. This observation is augmented in glycogen-depleted muscle $[13,16]$, indicating that IL- 6 production is related to metabolic demand. It is not known if $I L-6$ mRNA expression is higher in the muscles of patients with Type 2 diabetes and if $I L-6$ mRNA in human skeletal muscle is stimulated by insulin.
The role of TNF $\alpha$ in the pathogenesis of insulin resistance has been the subject of numerous investigations. Specifically, plasma TNF $\alpha$ is increased in patients with Type 2 diabetes [17, 18, 19] whereas its expression is increased in the adipose [20] and skeletal muscle [4] tissue of such patients. In vitro, TNF $\alpha$ decreases the expression of GLUT4 in 3T3-L1 adipocytes [21] and it inhibits the activation of the major target of the insulin receptor, IRS-1 [22, 23, 24], although it does not impair glucose transport in the short term [25]. Less, however, is known as to the effect of TNF $\alpha$ on insulin resistance in humans in vivo, but a positive correlation has been observed between $T N F \alpha$ mRNA expression in skeletal muscle and insulin action in humans [4]. In contrast, administration of a TNF $\alpha$-neutralising antibody for 4 weeks had no effect on improving insulin sensitivity [26]. Whether the increased TNF $\alpha$ concentrations in plasma correlate with insulin action in patients with Type 2 diabetes is not clear. Since TNF $\alpha$ directly interferes with activation of insulin signalling proteins, we hypothesised that its expression and circulating concentrations would be related to the degree of insulin resistance. Therefore, we measured the expression and circulating concentrations of IL-6 and TNF $\alpha$ in skeletal muscle of Type 2 diabetic patients and healthy control subjects, both at rest and after a hyperinsulinaemiceuglycaemic clamp.

\section{Subjects and methods}

Subjects. This study was completed in two stages, the first (CLAMP1) comprised 23 male volunteers (D1, 6 patients with Type 2 diabetes; CON1, six healthy, sedentary, age- and BMImatched control subjects; and YOUNG, eleven younger control subjects), and the second, CLAMP2, comprised 13 male volunteers (D2, six patients with Type 2 diabetes; and CON2, seven healthy, sedentary age- and BMI-matched control subjects). The experimental protocols were approved by the $\mathrm{Hu}-$ man Ethics Committee of RMIT University (CLAMP1) and the Ethics Committee of Copenhagen and Fredriksberg Communities, Denmark (CLAMP2), and were carried out according to the 'Declaration of Helsinki'. The physical characteristics of the study participants are presented in Table 1 . Normal glucose tolerance was confirmed in control subjects by an

Table 1. Subject physical characteristics of groups

\begin{tabular}{|c|c|c|c|c|c|c|c|}
\hline & \multirow[t]{2}{*}{ Age } & \multirow[t]{2}{*}{ BMI } & \multirow[t]{2}{*}{$\%$ Fat } & \multirow[t]{2}{*}{ Weight } & \multicolumn{3}{|c|}{ Basal plasma concentrations } \\
\hline & & & & & Glucose $\left(\mathrm{mmol} \cdot \mathrm{l}^{-1}\right)$ & Insulin $\left(\mathrm{pmol} \cdot \mathrm{1}^{-1}\right)$ & NEFA $\left(\mathrm{mmol} \cdot \mathrm{l}^{-1}\right)$ \\
\hline CON1 & $49.7 \pm 1.6$ & $27.6 \pm 1.0$ & $26.0 \pm 3.9$ & $85.7 \pm 3.1$ & $4.4 \pm 0.1 *$ & $61.1 \pm 4.6^{*}$ & $0.79 \pm 0.07 *$ \\
\hline YOUNG & $25.1 \pm 1.2 * \#$ & $23.6 \pm 0.5^{* \#}$ & $13.3 \pm 2.6$ & $77.2 \pm 2.4^{* \#}$ & $4.2 \pm 0.1 *$ & $38.8 \pm 3.2 *$ & $0.74 \pm 0.06 *$ \\
\hline D2 & $58.3 \pm 2.4$ & $32.5 \pm 1.6$ & - & $106.0 \pm 5.8$ & $8.7 \pm 0.8$ & $86.6 \pm 29.4$ & $0.99 \pm 0.11$ \\
\hline
\end{tabular}

YOUNG, Young control; CON1 and CON2, old control subjects; D1 and D2, Type 2 diabetic patients. *Different from D; \#different from $\mathrm{CON}, p<0.05$ 
OGTT (75 g glucose). The patients with Type 2 diabetes had a mean time of $4 \pm 1$ years since diagnosis (range: 6 months to 10 years), and did not exercise regularly. Other than diabetes, none of the subjects had any significant medical problems, all were non-smokers and none were taking medications known to alter carbohydrate metabolism. Subjects were instructed to abstain from any form of vigorous physical activity for $36 \mathrm{~h}$ prior to an experiment, and to maintain their normal diet. The subjects reported to the laboratory after a 12 to 14-h overnight fast. All subjects except YOUNG were also matched for fitness levels, in that maximal oxygen uptake levels were not different (data not shown) and all were sedentary in that no subject in the older age group participated in any regular physical activity.

Assessment of body composition. In Series 1 whole body dual energy X-ray absorptiometry (DEXA; Lunar DPX, Lunar Radiation, Madison, Wis., USA) was used to measure total and regional tissue composition (body fat, lean tissue mass and bone mineral content). Prior to each scan, the DEXA was calibrated with known phantoms.

Euglycaemic-hyperinslinaemic clamp. To determine the relationship between the cytokines and insulin resistance we chose to determine whole-body insulin-stimulated glucose uptake using the euglycaemic-hyperinsulinaemic clamp (CLAMP) technique [27], since it has been described as 'the gold standard' as an index of insulin responsiveness [2]. However, such experiments are non-physiological because the supra-physiological doses of insulin totally suppress lipolysis. Therefore, the insulin dose chosen in the second experiment was relatively low $\left(7 \mathrm{mU} \cdot \mathrm{m}^{-2} \cdot \mathrm{min}^{-1}\right)$.

In CLAMP1 an antecubital vein was cannulated for infusion of glucose and insulin, and a hand vein was cannulated retrogradely for blood sampling. After baseline blood samples were collected, a percutaneous biopsy from the vastus lateralis muscle was obtained, immediately frozen in liquid nitrogen and stored at $-80{ }^{\circ} \mathrm{C}$ until subsequent extraction of mRNA. After resting for $5 \mathrm{~min}$, a primed $\left(9 \mathrm{mU} \cdot \mathrm{kg}^{-1}\right)$ continuous infusion of insulin (Actrapid, Novo Nordisk, Bagsværd Denmark) was started at a rate of $40 \mathrm{mU} \cdot \mathrm{m}^{-2} \cdot \mathrm{min}^{-1}$, and blood glucose concentration was measured at 5-min intervals throughout the clamp. A variable rate infusion of $20 \%$ glucose was used to maintain euglycaemia $\left(5 \mathrm{mmol} \cdot \mathrm{l}^{-1}\right)$ for the duration of the clamp (120 min). The blood glucose concentration in the diabetic subjects was allowed to decrease during the insulin infusion to $5 \mathrm{mmol} \cdot \mathrm{l}^{-1}$, and then maintained at this concentration for the remainder of the clamp. Samples $(2 \mathrm{ml})$ for subsequent determination of plasma cytokine concentrations were obtained every $30 \mathrm{~min}$, centrifuged and stored at $-80{ }^{\circ} \mathrm{C}$. Wholebody glucose uptake was calculated from the glucose infusion rate $\left(\mathrm{mg} \cdot \mathrm{kg}^{-1} \cdot \mathrm{min}^{-1}\right)$ required to maintain a blood glucose concentration of $5 \mathrm{mmol} \cdot \mathrm{l}^{-1}$. Since repeated biopsies within close proximity to one another do not alter the stress response at the second site [28], a second muscle biopsy was obtained $5 \mathrm{~cm}$ distal to the resting sample $120 \mathrm{~min}$ after the insulin infusion. To prevent a decrease in plasma potassium concentration during the clamp, $30 \mathrm{mmol} \mathrm{KCl}$ (Slow-K; Novartis, Sydney, NSW, Australia) was administered orally.

Before CLAMP2, subjects were cannulated as per CLAMP1 for glucose and insulin infusion, and also had cannulae placed in a femoral artery and femoral and subclavian veins for sampling of arterial blood and venous blood draining lower and upper extremities respectively. The remaining procedures were as described for CLAMP1, except venous and arterial samples were obtained every $60 \mathrm{~min}$, no tissue biopsies were obtained, and insulin was infused at $7 \mathrm{mU} \cdot \mathrm{m}^{-2} \cdot \mathrm{min}^{-1}$. Blood sampling lines were flushed regularly with normal saline to avoid clotting. Limb release of cytokines was determined as described previously [14].

Plasma cytokines and non-esterified fatty acids. Plasma concentrations of IL- 6 and TNF $\alpha$ were determined via quantitative sandwich ELISA using commercially available kits (R\&D Systems, Bio-scientific, Gymea, NSW, Australia), with interand intra-assay coefficient of variation, as specified by the manufacturer, of $7.4 \%$ and $7.8 \%$ (IL-6) and $6.7 \%$ and $13.3 \%$ $(\mathrm{TNF} \alpha)$ respectively. Plasma NEFA were analysed by an enzymatic colorimetric method (Wako, NEFAC, Tokyo, Japan) [29].

Cytokine mRNA expression. Muscle samples were extracted for total RNA, followed by determination of gene expression by real-time RT-PCR. Methods, primer/probe sequences and quantification are described elsewhere [29].

Statistical analyses. All data are presented as means \pm SEM. Group physical characteristics were analysed using ANOVA. To analyse changes over time between groups, a two-way repeated measures ANOVA was used. In Series 2 multivariate analyses of covariance (MANCOVA) were completed to determine if differences in the subjects' physical characteristics would account for a lack of difference between groups for plasma cytokine data. Newman-Kuels post-hoc tests were used where significant differences from ANOVA were shown. Significance was accepted as a $p$ value of less than 0.05 . All statistics were completed using Statistica software for windows (StatSoft, version 5.1, 1997, Statistica, Tulsa, Okla., USA).

\section{Results}

Glucose infusion rates (GIR) corrected for body mass are presented in Figure 1. In CLAMP1, the GIR in D1 was lower than that in CON1, and it was lower in both groups than that in YOUNG $(2.3 \pm 0.6 ; 7.8 \pm 0.7$ and $15.4 \pm 1.3 \mathrm{mg} \cdot \mathrm{kg}^{-1} \cdot \mathrm{min}^{-1}$ respectively, $\left.p<0.05\right)$. In CLAMP2, GIR was lower in D2 than in CON2 $\left(0.86 \pm 0.05\right.$ and $1.26 \pm 0.07 \mathrm{mg} \cdot \mathrm{kg}^{-1} \cdot \mathrm{min}^{-1}$ respectively, $p<0.05)$.

Neither skeletal muscle $I L-6$ nor $T N F \alpha$ mRNA were different in groups at rest or after CLAMP1. Insulin stimulation did not affect the mRNA expression of these cytokines in any group (Fig. 2). Plasma IL-6 was lower $(p<0.05)$ in YOUNG both before and throughout CLAMP1 than in D1 and CON1 (Fig. 3). Despite the differences in GIR when comparing D1 with CON1, no differences were observed in plasma IL-6 at any point when comparing these groups.

Arterial IL-6 and TNF $\alpha$ levels and release of these from the arm and leg from CLAMP2 are shown in Figures 4 and 5. Concordant with CLAMP1, no differences were observed in the circulating concentrations of these cytokines in D2 compared with CON2. Furthermore, insulin did not stimulate the release of either cytokine in either D2 or CON2. These data suggest that a substantial amount of IL-6 $\left(\sim 1 \mathrm{ng} \cdot \mathrm{min}^{-1}\right)$, but not $\mathrm{TNF} \alpha\left(<100 \mathrm{pg} \cdot \mathrm{min}^{-1}\right)$ are released from the limbs. However, subjects in Series 2 differed between 
a
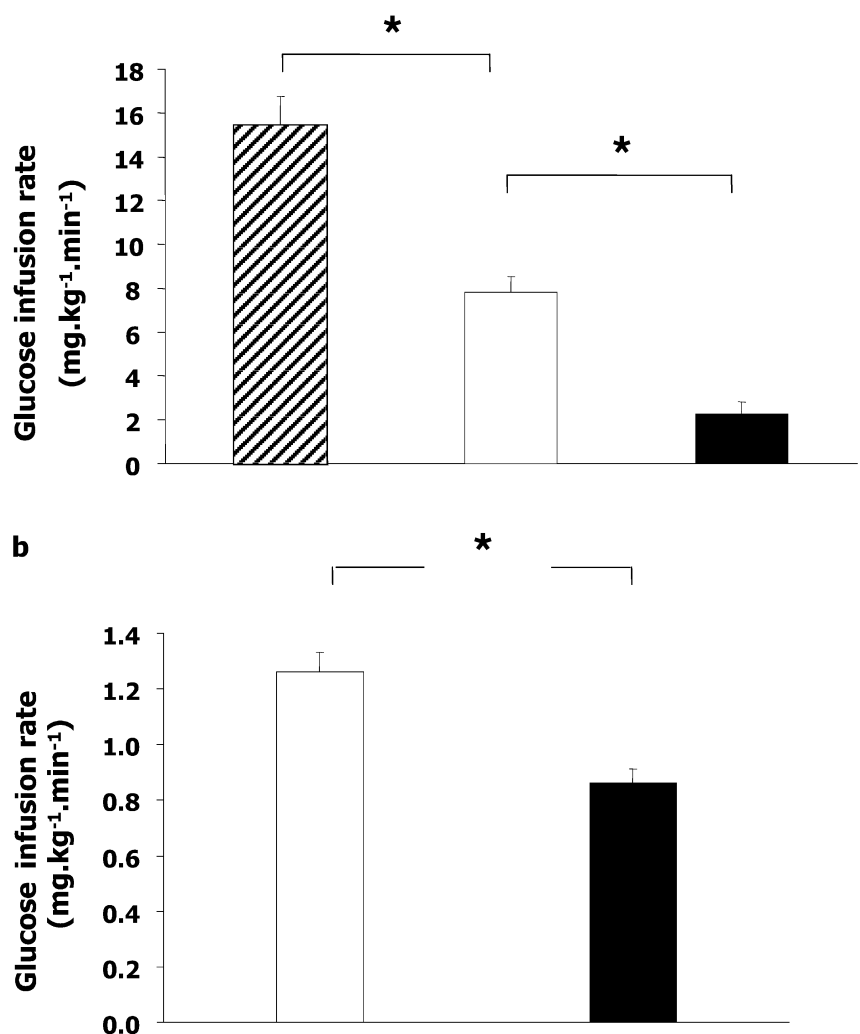

Fig. 1. Glucose infusion rates during the final $30 \mathrm{~min}$ of 120-min (CLAMP1) (a) and 240-min (CLAMP2) (b) hyperinsulinaemic-euglycaemic clamp $\left(\mathrm{mg} \cdot \mathrm{kg}^{-1} \cdot \mathrm{min}^{-1}\right)$ in young control subjects (YOUNG; hatched bars), Type 2 diabetic patients (D1, D2; closed bars) and old control subjects (CON1, CON2; open bars). ${ }^{*} p<0.05$ compared to the other two groups

groups in age, weight and BMI (Table 1). Consequently, the statistical analyses for arterial, and leg and arm release of IL- 6 and TNF $\alpha$ were repeated, with these variables included as covariates. Again, no differences were found between groups for any of these variables $(p>0.05)$.

Linear regression analyses were completed to determine relationships between insulin-stimulated glucose infusion rates and skeletal muscle mRNA concentrations of $I L-6$ and $T N F \alpha$ from CLAMP1. No significant correlations were found between these variables (IL-6 mRNA vs GIR, $r=0.48 ; T N F \alpha$ mRNA vs GIR, $r=0.4 ; p>0.15)$. Further regression analyses were completed comparing circulating cytokine levels with GIR. To include subjects from both CLAMP1 and CLAMP2, glucose disposal rate units were converted to $\mu \mathrm{g} \cdot \mathrm{kg}^{-1} \cdot \mathrm{min}^{-1}$ insulin infusion $\mathrm{rate}^{-1}$ to allow for correction of the different infusion rates in the two studies. Regression analysis showed a significant inverse correlation between resting plasma IL-6 levels and GIR $(r=0.54, p<0.05)$ when all subjects were included. This relationship was abolished when corrected for BMI (exclusion of subjects with BMI $\left.<25 \mathrm{~kg} \cdot \mathrm{m}^{-2} ; r=0.04, p=0.87\right)$. A similar comparison

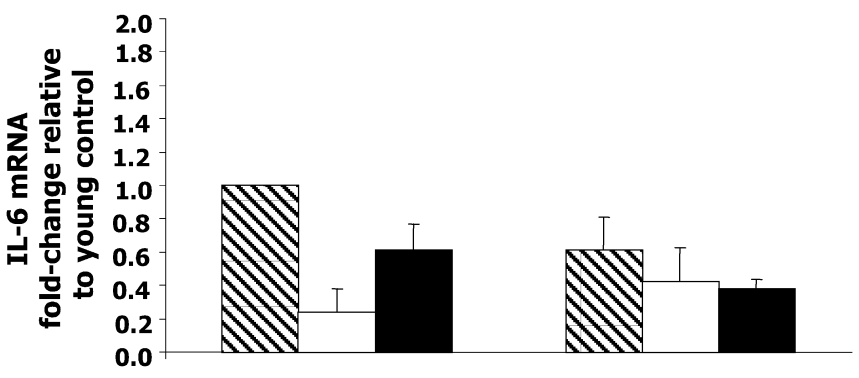

b

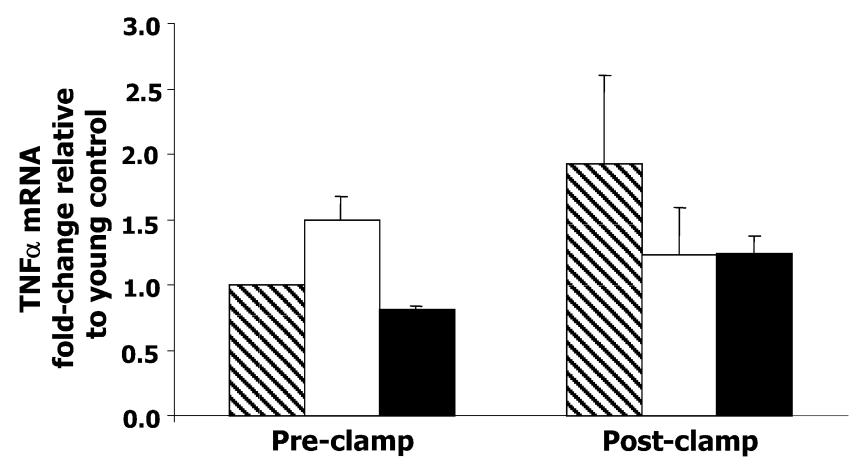

Fig. 2. Skeletal muscle IL-6 (a) and TNF $\alpha$ (b) mRNA before and after 120-min hyperinsulinaemic-euglycaemic clamp. Hatched bar, YOUNG; open bar, CON1; closed bar, D1
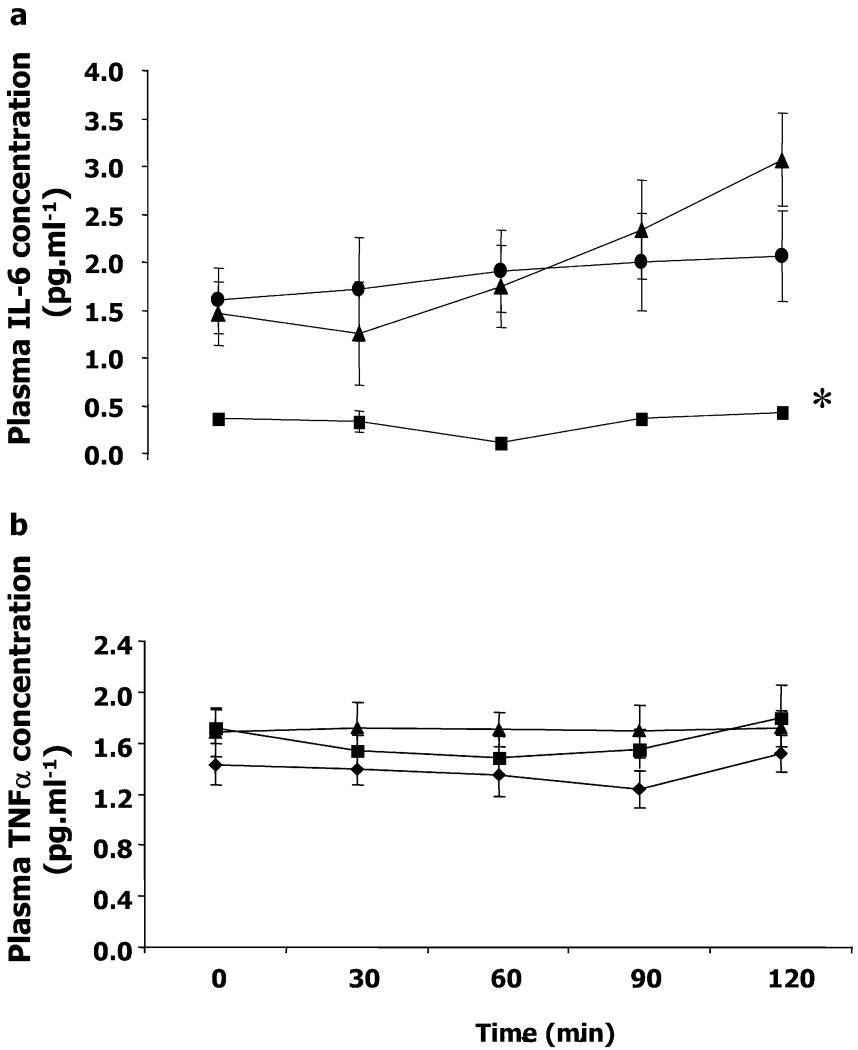

Fig. 3. Plasma concentrations of IL-6 (a) and TNF $\alpha$ (b) during 120-min hyperinsulinaemic-euglycaemic clamp. ${ }^{*}=$ Significantly different compared to CON1 and D1, $p<0.05$; squares, YOUNG; circles, CON1; triangles, D1 

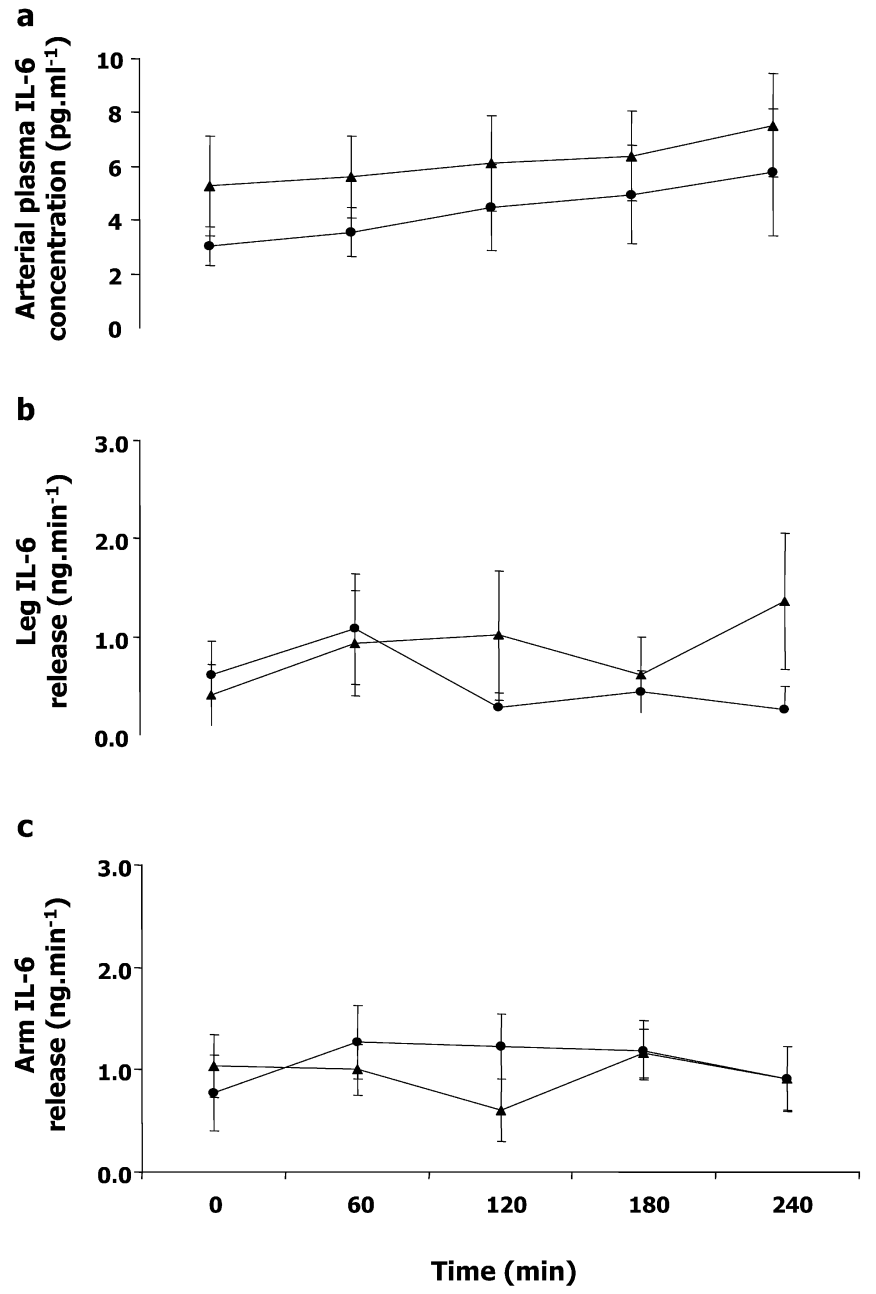

Fig. 4. Arterial IL-6 concentrations (a) during 240-min euglycaemic-hyperinsulinaemic clamp. (b) Release of IL-6 from the leg. (c) Release of IL-6 from the arm. Circles, CON2; triangles, D2

showed no relationship between GIR and plasma TNF $\alpha$, whether corrected for BMI $(r=<0.001, p=0.95)$ or not $(r=0.18, p=0.3)$ (Fig. 6). A significant correlation $\left(r=0.85, p<1.0 \times 10^{-8}\right)$ was observed between resting plasma IL-6 concentrations and BMI (Fig. 7), and this relationship remained significant when corrected for BMI $(r=0.76, p<0.001)$. When comparing plasma TNF $\alpha$ concentrations versus BMI (Fig. 7) an inverse relationship was observed $(r=0.35, p<0.05)$, although this correlation was not observed after correction for BMI $(r=0.36, p=0.1)$.

Since BMI is a measure that also relates to muscle mass, it is one potential determinant of insulin sensitivity. To provide further evidence that fat mass per se was related to plasma IL-6 we did correlations between plasma IL- 6 and percent body fat in Series 1 whereby DEXA scans were carried out. Consistent with our observation when correlating plasma IL-6

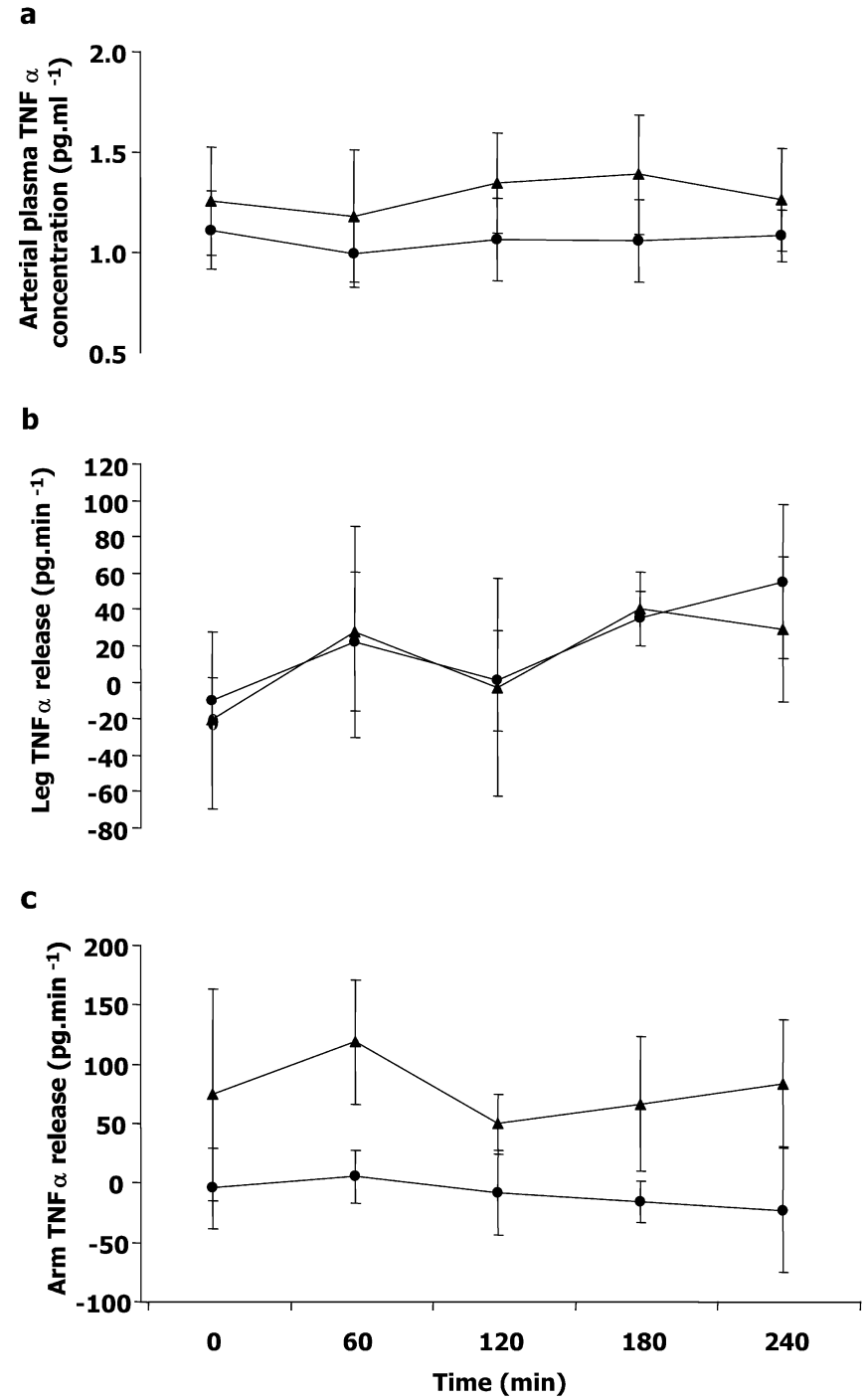

Fig. 5. Arterial TNF $\alpha$ concentrations (a) during 240-min euglycaemic-hyperinsulinaemic clamp. (b) Release of TNF $\alpha$ from the leg. (c) Release of TNF $\alpha$ from the arm. Circles, CON2; triangles, D2

with BMI using all subjects (Fig.7), a significant correlation $(r=0.71 ; p=0.01)$ was observed between resting plasma IL-6 and total body fat $(\mathrm{kg})$ in subjects in Series 1. In contrast, no such relationship was observed when correlating lean body mass with resting plasma IL-6 in subjects in Series $1(r=0.12, p=0.59)$.

\section{Discussion}

Our results show that increased plasma concentrations of IL-6 observed in patients with Type 2 diabetes and control subjects matched for age are not related to insulin-stimulated glucose infusion rates, but are rather an index of adiposity. In contrast with many studies $[3,4,5]$, these results show that despite the markedly different rates of glucose infusion when comparing our populations, there was no evidence that TNF $\alpha$ 
a

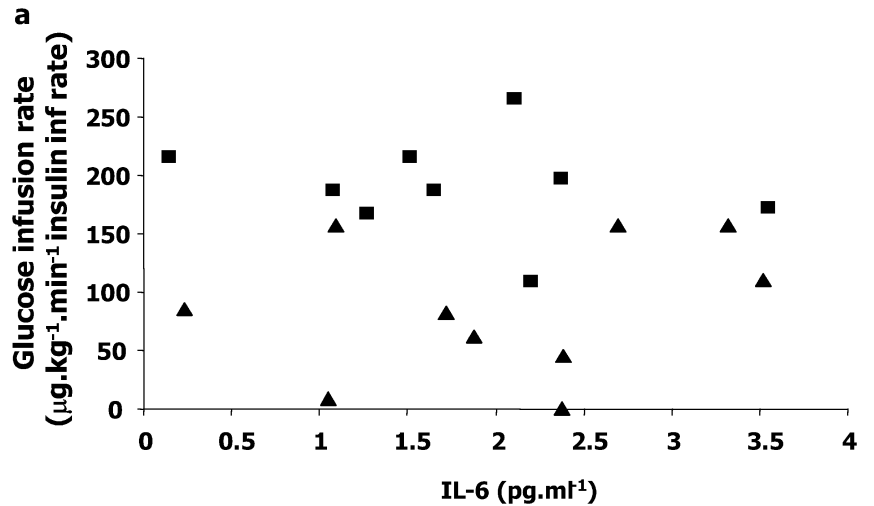

b

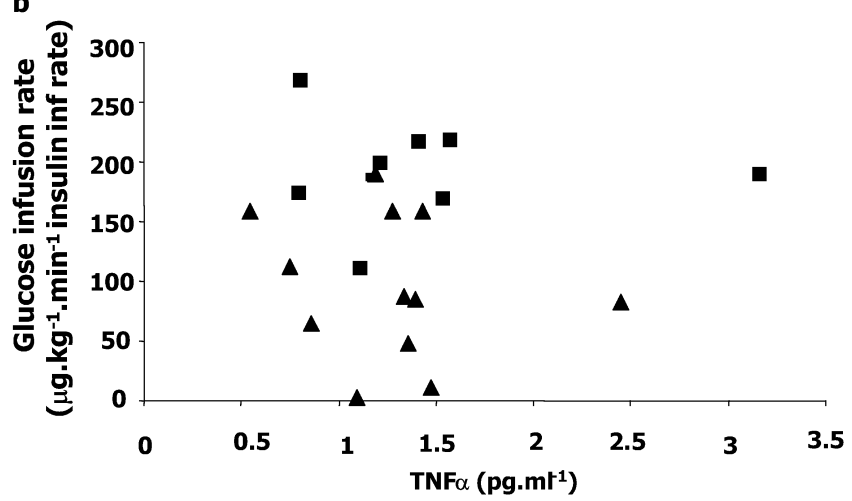

Fig. 6. Linear regression relationship between resting plasma IL-6 (a) and TNF $\alpha$ (b) concentrations and glucose infusion rate corrected for BMI. IL-6 $r=0.04, p=0.87$; TNF $\alpha r=<0.001$, $p=0.95$. Triangles, D1/2; squares, CON1/2

was increased in patients diagnosed with Type 2 diabetes, nor was there evidence linking its expression to insulin responsiveness. Furthermore, our results suggest that substantial amounts of IL-6, but not TNFo are released from tissue(s) within the limbs.

The data from our study are in contrast with two recent reports that showed a direct correlation between plasma IL-6 concentrations [3] and adipose tissue IL-6 content [2] with insulin resistance. Our study is in agreement with another study which used a very homogeneous group of subjects (obese, non-diabetic Pima Indians) whereby fasting plasma IL-6 concentrations were related to percentage body fat, but not insulin sensitivity when corrected for body fat concentrations [30]. In our study, despite a three-fold higher GIR in CON1 than D1, no differences in plasma IL-6 content were observed when comparing the groups, and no correlation was observed between basal IL-6 levels and GIR in subjects that were matched for BMI. This, combined with a very strong correlation between basal IL-6 levels and BMI-one that remains after exclusion of subjects who have normal BMIs - suggests that IL-6 does not impair insulin-stimulated glucose disposal. On closer examination, however, there is an explanation for these anomalous results. In the two previous studies $[2,3]$, the subjects had a BMI of about $35 \mathrm{~kg} \cdot \mathrm{m}^{-2}$. Our data suggest a similar correla- a

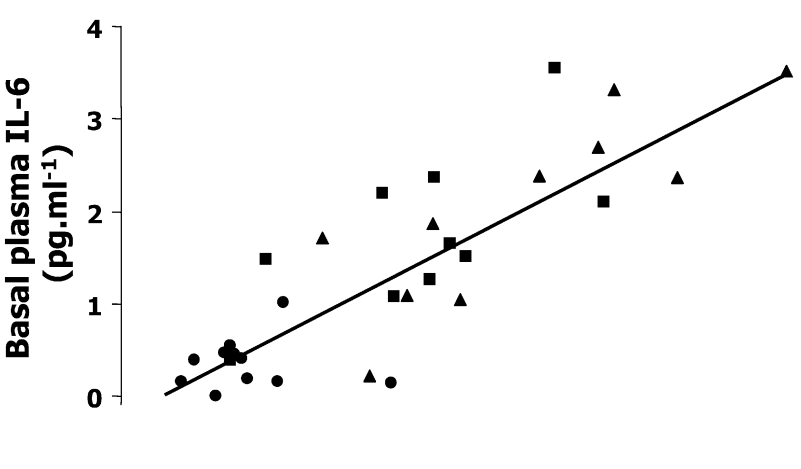

b

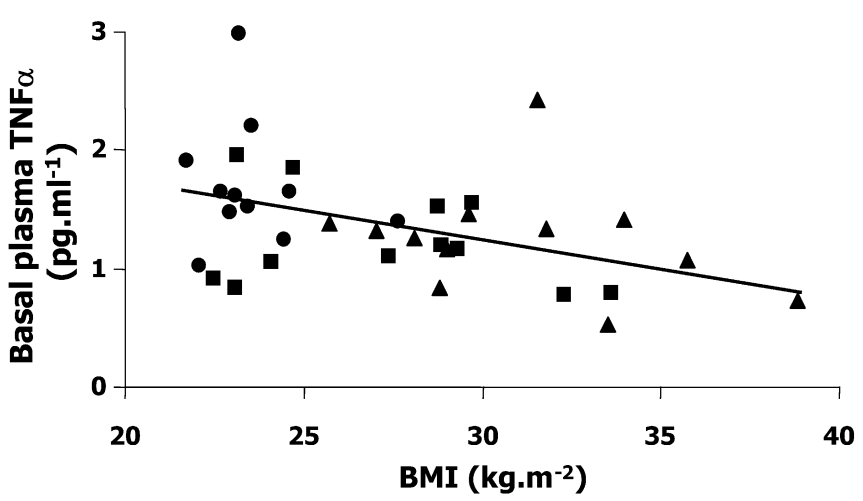

Fig. 7. Linear regression relationship between resting plasma IL-6 (a) and TNF $\alpha$ (b) concentrations and BMI. IL-6: $r=0.85$, $p<1.0 \times 10^{-8}$; TNF $\alpha$ : $r=0.35, p<0.05$. Circles, YOUNG; triangles, D1/2; squares, CON1/2

tion is evident over a wide range of BMIs. However, because the plasma IL-6 was so strongly related to BMI, it was important to correct for BMI when correlating GIR with basal plasma IL-6. There was no relationship between these two parameters when subjects were matched for BMI. Taken together, therefore, the studies suggest that IL-6 is only related to insulin action when comparing normal weight subjects with overweight patients.

Since IL-6 secretion from adipose tissue and circulating IL-6 are a function of the degree of fat mass [3] we suggest that a threshold exists whereby the circulating IL-6 must be chronically increased at reasonably high concentrations to have an adverse effect on insulin receptor signalling. In a recent paper [31] the IL-6 dose that reduced tyrosine phosphorylation of IRS-1, the association of the p85 subunit of phosphatidylinositol (PI) 3-kinase with IRS-1 and the insulin-dependent activation of protein kinase B/Akt, in HepG2 cells and hepatocytes was $20 \mathrm{ng} \cdot \mathrm{ml}^{-1}$, whereas basal plasma IL-6 concentrations measured in Type 2 diabetic patients in our study were $<5 \mathrm{pg} \cdot \mathrm{ml}^{-1}$. In addition, acutely increasing IL-6 to high physiological levels by rhIL-6 infusion did not impair basal glucose disposal [9], whereas it actually enhanced it in patients with renal carcinoma [32]. Furthermore, an IL-6 knockout mouse that became obese and insulin-resistant signifi- 
cantly improved glucose tolerance when the basal IL-6 levels were restored with recombinant mouse IL-6 treatment. Therefore, we suggest that IL-6 may only be involved in impairing insulin action if it is increased chronically, and to very high levels, in obese subjects. At the very least, from a clinical perspective, our data suggest that one must be cautious in using basal plasma IL-6 levels as a marker of insulin resistance.

We have shown previously that in a rat model of insulin resistance, IL-6 mRNA increases in skeletal muscle in response to insulin stimulation compared with control animals [15]. We hypothesised that this was due to the defect in insulin-stimulated PI3-kinase activity, which can inhibit IL-6 expression [33]. In the present study IL-6 expression was not increased in D1 after insulin stimulation, a result consistent with a recent study in young healthy humans [34]. Since the insulin and cytokine signalling pathways in both rodents and humans are similar, it is likely that the single genetic defect that resulted in insulin resistance in the rodent model played a role in signalling the expression of IL-6 after insulin stimulation. In contrast, the polygenic nature and the environmental factors associated with Type 2 diabetes may account for the lack of increase in skeletal muscle $I L-6$ mRNA in response to insulin in our patient population. Another explanation could be that the insulin dose we administered was a high physiological dose, one that can be reached with ingestion of a large bolus of carbohydrate, as shown previously [35]. This can be evidenced by our lack of complete suppression of plasma fatty acids, which would be the case after a supra-physiological insulin dose during a clamp experiment. Potentially, the insulin dose was not sufficient to activate PI3-kinase to the extent that it could inhibit IL-6 transcription. This remains to be determined. Furthermore, we had a relatively small sample size for measures of skeletal muscle mRNA expression and this was a limitation to this study, which may have resulted in a type 2 error. However, a recent study [34] showed that insulin had no effect on skeletal muscle $I L-6$ mRNA. Therefore, we are confident of our results with respect to IL-6 mRNA, despite the relatively low number of subjects.

We hypothesised that TNF $\alpha$ expression and circulating concentrations of this cytokine would be related to the degree of insulin resistance. Our results showed that neither plasma TNF $\alpha$ concentrations nor $T N F \alpha$ mRNA in skeletal muscle were different when comparing groups. Our observation that basal plasma TNF $\alpha$ was similar when comparing Type 2 diabetic patients with control subjects is in agreement with some [3, 36, 37] but not all [18, 19, 38, 39] studies. No previous studies have examined the relationship between plasma TNF $\alpha$ and insulin responsiveness during a hyperinsulinaemic-euglycaemic clamp, but our data demonstrate no association in our patients. There has only been one previous study that measured $T N F \alpha$ mRNA in Type 2 diabetic skeletal muscle from humans [4]. In that study, the skeletal muscle from patients with Type 2 diabetes expressed more $T N F \alpha$ mRNA than the control subjects. Furthermore, a negative correlation existed between skeletal muscle $T N F \alpha$ mRNA expression and GIR. In our study no such results were observed, and given that the subject characteristics were similar between the two studies, we have no explanation for these anomalous results. This is especially puzzling considering that, if anything, we find that increased BMI is associated with reduced plasma TNF $\alpha$ levels, and it is well accepted that TNF $\alpha$ is produced by adipocytes, and it inhibits insulin action in vitro. The only explanation we can suggest for such a finding is that IL-6 produced in skeletal muscle suppresses endotoxin-induced TNF $\alpha$ production [40]. Therefore, it can be hypothesised that IL-6 produced by adipocytes suppresses TNF $\alpha$ produced by the same tissue. We also cannot exclude the possibility that post-transcriptional modifications occur, such that TNF $\alpha$ mRNA levels differ from protein levels in skeletal muscle. Potentially, TNF $\alpha$ protein may interact or be activated by further proteins within Type 2 diabetic skeletal muscle in a different manner to that in healthy skeletal muscle. Therefore, in vivo measurement of TNF $\alpha$ protein content in Type 2 diabetic skeletal muscle, the role of circulating $\mathrm{TNF} \alpha$ protein, and its interaction with insulin signalling proteins is required to reconcile the role of intramuscular TNF $\alpha$ expression and the pathogenesis of insulin resistance. In this vein, another study [26] showed that neutralisation of circulating TNF $\alpha$ does not improve insulin sensitivity in Type 2 diabetic patients. This study, combined with our data, suggests that, in vivo, circulating TNF $\alpha$ levels have no effect on insulin action, and that any effect that TNF $\alpha$ has must involve local autocrine/paracrine effects on insulin-sensitive tissues, and that the mRNA expression may not be representative of its content or actions within the cell.

It is apparent from present and previous data that the role of TNF $\alpha$ in the pathogenesis of insulin resistance is equivocal. Although the results from our study cannot resolve the confusion, it is worth noting the recent data [41] by authors who demonstrated that high doses of TNF $\alpha\left(1-2.5 \mathrm{nmol} / \mathrm{l}\right.$, or $\left.>15 \mathrm{ng} \cdot \mathrm{ml}^{-1}\right)$ inhibited the activation of insulin signalling proteins IRS- 1 and Akt, whereas lower doses $(150 \mathrm{pmol} / \mathrm{l}$, or $\left.\sim 2 \mathrm{ng} \cdot \mathrm{ml}^{-1}\right)$ did not. Furthermore, short-term $(<8 \mathrm{~h})$ exposure of rat soleus and epitrochlearis muscles to $\mathrm{TNF} \alpha$ neither impairs insulin signalling nor glucose uptake [25]. Therefore, TNF $\alpha$ may only play a role in the pathogenesis of insulin resistance in severe cases of Type 2 diabetes where inflammation and, hence TNF $\alpha$ levels, are chronically and abnormally high. This suggestion is, however, speculative and further human in vivo work is required to further clarify the role, if any, of TNF $\alpha$ in insulin resistance.

Previous work has shown that IL-6 $[8,11]$, but not TNF $\alpha$ [4], is released from subcutaneous abdominal 
adipose tissue. Abdominal adipose tissue has been implicated as a cause of insulin resistance in cases where it is in excess [42], and due to factors it may release into the circulation [43]. We show for the first time that IL-6 is released from the arm and leg in large quantities, but TNF $\alpha$ is not. Limbs contain a number of tissues, although unlike the abdominal/thoracic region, it is realistic to expect that resting IL-6 release is from metabolic tissues since other tissues that produce significant amounts of IL-6 are absent. IL-6 is released from leg muscle during metabolic stress [14]. However, because of the age of the subjects in this data set ( $\sim 50$ years), the muscle mass of the leg is likely to be much greater than that of the arm, yet IL-6 release levels are similar between the arm and leg. Therefore, it is more tempting to speculate that the release of IL-6 is derived from adipose tissue. Of note, in our study circulating IL-6 was not increased by insulin stimulation after either $2 \mathrm{~h}$ (Series 1) or $4 \mathrm{~h}$ (Series 2) of insulin stimulation. In contrast, a recent study showed that plasma IL-6 increased during $6 \mathrm{~h}$ of insulin infusion [34]. It is possible, therefore, that prolonged treatment with insulin increases plasma IL-6. However, one cannot rule out the possibility that the increase in plasma IL-6 reported in the previous study [34] was due to circadian rhythms or other factors independent of the insulin, because a control trial was not carried out in either the present or previous [34] experiments. To this end we have observed that $7 \mathrm{~h}$ of saline infusion increases plasma IL-6 content (Wolsk-Petersen, Carey, Steinberg, Macaulay, Febbraio, Pedersen, unpublished observations).

In conclusion, our data show that increased plasma concentrations of IL- 6 in patients with Type 2 diabetes are not related to insulin-stimulated glucose disposal but are an indicator of fat mass. Furthermore, despite the markedly lower rates of glucose disposal in patients with Type 2 diabetes during a hyperinsulinaemic-euglycaemic clamp, there was no evidence that $\mathrm{TNF} \alpha$ was involved in the process of insulin responsiveness.

Acknowledgements. We wish to thank the subjects for participating in this demanding study and we wish to acknowledge the technical assistance of Sally Clarke, Dr David Newman, Kate Greenway, Birgitte Jessen, Ruth Rousing and Hanne Willumsen. This study was supported by the National Health and Medical Research Council of Australia (MAF), Masterfoods, a division of Mars (JAH) and the Danish Medical Research Council (BS). Mark A. Febbraio is supported by a Senior Research Fellowship from The National Health and Medical Research Council of Australia.

\section{References}

1. Bastard JP, Jardel C, Bruckert E et al. (2000) Elevated levels of interleukin 6 are reduced in serum and subcutaneous adipose tissue of obese women after weight loss. J Clin Endocrinol Metab 85:3338-3342
2. Bastard JP, Maachi M, Van Nhieu JT et al. (2002) Adipose tissue IL-6 content correlates with resistance to insulin activation of glucose uptake both in vivo and in vitro. J Clin Endocrinol Metab 87:2084-2089

3. Kern PA, Ranganathan S, Li C, Wood L, Ranganathan G (2001) Adipose tissue tumor necrosis factor and interleukin-6 expression in human obesity and insulin resistance. Am J Physiol Endocrinol Metab 280:E745-E751

4. Saghizadeh M, Ong JM, Garvey WT, Henry RR, Kern PA (1996) The expression of TNF alpha by human muscle. Relationship to insulin resistance. J Clin Invest 97:11111116

5. Uysal KT, Wiesbrock SM, Marino MW, Hotamisligil GS (1997) Protection from obesity-induced insulin resistance in mice lacking TNF-alpha function. Nature 389:610614

6. Fernandez-Real JM, Broch M, Vendrell J et al. (2000) Interleukin-6 gene polymorphism and insulin sensitivity. Diabetes 49:517-520

7. Pickup JC, Mattock MB, Chusney GD, Burt D (1997) NIDDM as a disease of the innate immune system: association of acute-phase reactants and interleukin- 6 with metabolic syndrome X. Diabetologia 40:1286-1292

8. Lyngso D, Simonsen L, Bulow J (2002) Interleukin-6 production in human subcutaneous abdominal adipose tissue: the effect of exercise. J Physiol 543:373-378

9. Steensberg A, Fischer CP, Sacchetti M et al. (2003) Acute interleukin-6 administration does not impair muscle glucose uptake or whole-body glucose disposal in healthy humans. J Physiol 548:631-638

10. Wallenius V, Wallenius K, Ahren B et al. (2002) Interleukin-6-deficient mice develop mature-onset obesity. Nat Med 8:75-79

11. Mohamed-Ali V, Goodrick S, Rawesh A et al. (1997) Subcutaneous adipose tissue releases interleukin-6, but not tumor necrosis factor-alpha, in vivo. J Clin Endocrinol Metab 82:4196-4200

12. Febbraio MA, Pedersen BK (2002) Muscle-derived interleukin-6: mechanisms for activation and possible biological roles. FASEB J 16:1335-1347

13. Keller C, Steensberg A, Pilegaard H et al. (2001) Transcriptional activation of the IL-6 gene in human contracting skeletal muscle: influence of muscle glycogen content. FASEB J 15:2748-2750

14. Steensberg A, van Hall G, Osada T, Sacchetti M, Saltin B, Pedersen BK (2000) Production of interleukin-6 in contracting human skeletal muscles can account for the exercise-induced increase in plasma interleukin-6. J Physiol 529:237-242

15. Carey AL, Lamont B, Andrikopoulos S, Koukoulas I, Proietto J, Febbraio MA (2003) Interleukin-6 gene expression is increased in insulin-resistant rat skeletal muscle following insulin stimulation. Biochem Biophys Res Commun 302:837-840

16. Steensberg A, Febbraio MA, Osada T et al. (2001) Interleukin-6 production in contracting human skeletal muscle is influenced by pre-exercise muscle glycogen content. J Physiol 537:633-639

17. Winkler G, Lakatos P, Salamon F et al. (1999) Elevated serum TNF-alpha level as a link between endothelial dysfunction and insulin resistance in normotensive obese patients. Diabet Med 16:207-211

18. Zinman B, Hanley AJ, Harris SB, Kwan J, Fantus IG (1999) Circulating tumor necrosis factor-alpha concentrations in a native Canadian population with high rates of type 2 diabetes mellitus. J Clin Endocrinol Metab 84:272278 
19. Pfeiffer A, Janott J, Mohlig M et al. (1997) Circulating tumor necrosis factor alpha is elevated in male but not in female patients with type II diabetes mellitus. Horm Metab Res 29:111-114

20. Hotamisligil GS, Shargill NS, Spiegelman BM (1993) Adipose expression of tumor necrosis factor-alpha: direct role in obesity-linked insulin resistance. Science 259:87-91

21. Stephens JM, Pekala PH (1992) Transcriptional repression of the C/EBP-alpha and GLUT4 genes in 3T3-L1 adipocytes by tumor necrosis factor-alpha. Regulations is coordinate and independent of protein synthesis. J Biol Chem 267:13580-13584

22. Hotamisligil GS, Murray DL, Choy LN, Spiegelman BM (1994) Tumor necrosis factor alpha inhibits signaling from the insulin receptor. Proc Natl Acad Sci USA 91:48544858

23. Hotamisligil GS, Peraldi P, Budavari A, Ellis R, White MF, Spiegelman BM (1996) IRS-1-mediated inhibition of insulin receptor tyrosine kinase activity in TNF-alpha- and obesity-induced insulin resistance. Science 271:665-668

24. Stephens JM, Lee J, Pilch PF (1997) Tumor necrosis factor-alpha-induced insulin resistance in 3T3-L1 adipocytes is accompanied by a loss of insulin receptor substrate- 1 and GLUT4 expression without a loss of insulin receptor-mediated signal transduction. J Biol Chem 272:971-976

25. Nolte LA, Hansen PA, Chen MM, Schluter JM, Gulve EA, Holloszy JO (1998) Short-term exposure to tumor necrosis factor-alpha does not affect insulin-stimulated glucose uptake in skeletal muscle. Diabetes 47:721-726

26. Ofei F, Hurel S, Newkirk J, Sopwith M, Taylor R (1996) Effects of an engineered human anti-TNF-alpha antibody (CDP571) on insulin sensitivity and glycemic control in patients with NIDDM. Diabetes 45:881-885

27. DeFronzo RA, Tobin JD, Andres R (1979) Glucose clamp technique: a method for quantifying insulin secretion and resistance. Am J Physiol Endocrinol Metab 237:E214-E223

28. Febbraio MA, Steensberg A, Fischer CP, Keller C, Hiscock N, Pedersen BK (2002) IL-6 activates HSP72 gene expression in human skeletal muscle. Biochem Biophys Res Commun 296:1264-1266

29. Steensberg A, Keller C, Starkie RL, Osada T, Febbraio MA, Pedersen BK (2002) IL-6 and TNF-alpha expression in, and release from, contracting human skeletal muscle. Am J Physiol Endocrinol Metab 283:E1272-E1278

30. Vozarova B, Weyer C, Hanson K, Tataranni PA, Bogardus C, Pratley RE (2001) Circulating interleukin-6 in relation to adiposity, insulin action, and insulin secretion. Obes Res 9:414-417

31. Senn JJ, Klover PJ, Nowak IA, Mooney RA (2002) Interleukin-6 induces cellular insulin resistance in hepatocytes. Diabetes 51:3391-3399
32. Stouthard JM, Romijn JA, van der Poll T et al. (1995) Endocrinologic and metabolic effects of interleukin-6 in humans. Am J Physiol Endocrinol Metab 268:E813-E819

33. Birkenkamp KU, Esselink MT, Kruijer W, Vellenga E (2000) An inhibitor of PI3-K differentially affects proliferation and IL-6 protein secretion in normal and leukemic myeloid cells depending on the stage of differentiation. Exp Hematol 28:1239-1249

34. Krogh-Madsen R, Plomgaard P, Keller P, Keller C, Pedersen BK (2004) Insulin stimulates interleukin-6 and tumor necrosis factor-\{alpha\} gene expression in human subcutaneous adipose tissue. Am J Physiol Endocrinol Metab 286:E234-E238

35. Febbraio MA, Keenan J, Angus DJ, Campbell SE, Garnham AP (2000) Preexercise carbohydrate ingestion, glucose kinetics, and muscle glycogen use: effect of the glycemic index. J Appl Physiol 89:1845-1851

36. Febbraio MA, Steensberg A, Starkie RL, McConell GK, Kingwell BA (2003) Contracting skeletal muscle releases IL-6, but not TNF- $\alpha$, in healthy subjects and patients with type 2 diabetes. Metabolism 52:939-954

37. Bluher M, Kratzsch J, Paschke R (2001) Plasma levels of tumor necrosis factor-alpha, angiotensin II, growth hormone, and IGF-I are not elevated in insulin-resistant obese individuals with impaired glucose tolerance. Diabetes Care 24:328-334

38. Paolisso G, Rizzo MR, Mazziotti G et al. (1998) Advancing age and insulin resistance: role of plasma tumor necrosis factor-alpha. Am J Physiol Endocrinol Metab 275:E294-E299

39. Winkler G, Salamon F, Salamon D, Speer G, Simon K, Cseh K (1998) Elevated serum tumour necrosis factoralpha levels can contribute to the insulin resistance in Type II (non-insulin-dependent) diabetes and in obesity. Diabetologia 41:860-861

40. Starkie R, Ostrowski SR, Jauffred S, Febbraio M, Pedersen BK (2003) Exercise and IL-6 infusion inhibit endotoxininduced TNF-alpha production in humans. FASEB J 17:884-886

41. Dietze D, Koenen M, Rohrig K, Horikoshi H, Hauner H, Eckel J (2002) Impairment of insulin signaling in human skeletal muscle cells by co-culture with human adipocytes. Diabetes 51:2369-2376

42. Miyazaki Y, Glass L, Triplitt C, Wajcberg E, Mandarino LJ, DeFronzo RA (2002) Abdominal fat distribution and peripheral and hepatic insulin resistance in type 2 diabetes mellitus. Am J Physiol Endocrinol Metab 283:E1135E1143

43. Hotamisligil GS (2000) Molecular mechanisms of insulin resistance and the role of the adipocyte. Int J Obes Relat Metab Disord [Suppl 4] 24:S23-S27 